\title{
REMBRANDT E O DIREITO PRIVADO
}

\author{
REMBRANDT AND THE PRIVATE LAW
}

Juliana Krueger Pela*

\begin{abstract}
Resumo:
Breves reflexões sobre temas de Direito Privado, inspiradas na obra $O$ projeto de Rembrandt, da historiadora da arte Svetlana Alpers.

Palavras-chave: Rembrandt. Propriedade Intelectual. Conceito de empresário. Títulos de crédito. Insolvência.
\end{abstract}

\begin{abstract}
:
Comments on Private Law subjects, inspired on the book Rembrandt's enterprise: the studio and the market, written by the art historian Svetlana Alpers.
\end{abstract}

Keywords: Rembrandt. Intellectual Property. Concept of entrepreneur. Negotiable debt instruments. Insolvency.

\section{Introdução}

Em 2010, tive contato com o livro O projeto de Rembrandt: o ateliê e o mercado, da historiadora Svetlana Alpers. ${ }^{1 / 2}$ Nele, a autora procura rever a biografia e a arte de Rembrandt para oferecer uma resposta alternativa aos questionamentos sobre a autenticidade de suas pinturas. E o faz - nas palavras de Claudia Valladão de Mattos, que introduz a edição brasileira - "assumindo uma atitude heterodoxa do ponto de vista da história da arte". ${ }^{3}$ Embora essa heterodoxia tenha gerado polêmica, ${ }^{4}$ não se pode deixar de reconhecer que, seja pelo método, seja pelo conteúdo, a obra é ousada e instigante.

Professora Doutora do Departamento de Direito Comercial da Faculdade de Direito da Universidade de São Paulo. Advogada em São Paulo. E-mail: julianapela@usp.br.

1 ALPERS, Svetlana. Rembrandt's enterprise: the studio and the market. Chicago: Chicago University Press, 1988; ALPERS, Svetlana. O projeto de Rembrandt: o ateliê e o mercado. Tradução de Vera Pereira. São Paulo: Companhia das Letras, 2010. A seguir, citado como O projeto de Rembrandt.

A edição brasileira tem sugestivamente a pintura "O cambista", também designada "Homem rico", como capa. Nela, um senhor - cercado por livros e por sacos de dinheiro - observa uma moeda contra a luz.

2 Professora Emérita do Departamento de História da Arte da Universidade da Califórnia - Berkeley.

3 ALPERS, Svetlana. O projeto de Rembrandt... cit., p. 11.

4 A obra foi alvo de inflamadas críticas, veiculadas por renomados críticos de arte e historiadores. Tais críticas consideraram a visão de Alpers sobre Rembrandt ideologicamente comprometida, afastando a arte de sua tradição humanista e estética. Além do exemplo citado na Introdução à edição brasileira (a crítica de Peter Sutton feita na The Burlington Magazine), há o ácido comentário de Hilton Kramer publicado na edição de abril de 1988 da Revista The New Criterion sob o irônico título de "Rembrandt as Warhol: Svetlana's Alpers Enterprise". Disponível em: <http://www.newcriterion.com/articles.cfm/Rembrandt-as-Warhol--SvetlanaAlpers-s--Enterprise--5992>. Acesso em: 11 abr. 2015. 
Mas o mais surpreendente é que esse livro de história da arte tenha despertado minhas reflexões sobre temas jurídicos. Talvez seja um hábito do ofício: o professor sempre procura encontrar, nos mais inusitados lugares, seu objeto de estudo.

Esse artigo é assim uma tentativa - despretensiosa e livre - de descrever esse encontro e as reflexões que se seguiram.

Para tanto, iniciarei com uma breve resenha da obra de Alpers e de sua visão sobre Rembrandt. A seguir, tratarei dos temas de Direito Privado que pude vislumbrar ao conhecer o "Projeto Rembrandt".

\section{Rembrandt segundo Alpers}

Instigada pelos questionamentos sobre a verdadeira autoria das obras atribuídas a Rembrandt, ${ }^{5}$ Alpers dedicou-se a investigar a particular forma de Rembrandt realizar e comercializar seus quadros na Holanda do século XVII. Constatou que não apenas na pintura, mas na organização da atividade, o "estilo Rembrandt" era muito diferente do estilo de outros pintores da época.

Assim como outros artistas, Rembrandt coordenava um ateliê composto por assistentes e aprendizes. Contudo, para Alpers, esse ateliê funcionava segundo regras e rotinas peculiares. As cenas retratadas nas pinturas costumavam ser teatralizadas pelos próprios assistentes, substituindo o usual emprego de clientes como modelos ${ }^{6}$ ou o recurso a ambientes externos. ${ }^{7}$ Há, assim, a prevalência de obras cujos cenário e contexto eram criados no próprio ateliê, denotando - segundo Alpers - o pleno domínio de Rembrandt sobre as atividades praticadas naquele espaço e sobre o conteúdo objeto da tela. ${ }^{8}$

O método de ensino praticado por Rembrandt também era diverso. Ao invés de ensinar os alunos a desenhar antes de pintar - por cópias de gravuras, como era comum à época - Rembrandt estimulava-os a desenhar a partir de modelos vivos, de narrativas próprias ou a copiar obras de sua própria autoria. ${ }^{9}$ Rembrandt não utilizava esses desenhos como estudos preparatórios, mas apenas com função didática. ${ }^{10}$

\footnotetext{
5 São recorrentes as notícias sobre a suspeita de que obras atribuídas a Rembrandt foram de fato confeccionadas por aprendizes. Há, paradoxalmente, "autorretratos" de Rembrandt de real autoria de terceiros. Trata-se do problema da "desatribuição" de obras de Rembrandt (ALPERS, Svetlana. O projeto de Rembrandt: o ateliê e o mercado. Tradução de Vera Pereira. São Paulo: Companhia das Letras, 2010. p. 21 e ss. e p. 310).

6 Nas palavras de Alpers: "Rembrandt atenua a distinção entre os que pagam para posar e os modelos que são pagos para fazê-lo" (ALPERS, Svetlana. O projeto de Rembrandt... cit., p. 228).

7 Conforme relatado no Cap. 2, intitulado "O modelo teatral", (ALPERS, Svetlana. O projeto de Rembrandt... cit.).

8 ALPERS, Svetlana. O projeto de Rembrandt... cit., p. 227.

$9 \quad$ Id. Ibid., p. 208 e 209.

$10 \quad$ Id. Ibid., p. 209.
} 
Além disso, aos alunos não cabia executar projetos iniciados por Rembrandt - como ocorria em outros ateliês - mas sim "fazer pinturas iguais às dele". ${ }^{11}$ Com essa prática, Rembrandt transmitia a seus discípulos sua técnica própria de pintura, o que permitiu a difusão ou dispersão do "estilo Rembrandt de pintar". ${ }^{2}$ Essa difusão foi tão ampla que Alpers chega a comparar esse estilo a uma marca.

Mas as principais particularidades dizem respeito à relação de Rembrandt com o mercado. Enquanto outros artistas inseriam-se no tradicional sistema do mecenato, ${ }^{13}$ Rembrandt adotou postura independente e procurou, nas palavras de Alpers, "produzir arte para novos mercados". ${ }^{14}$ Há diversos indícios dessa independência.

Em primeiro lugar, a relação de Rembrandt com seus clientes. Relata Alpers que ele costumava atrasar a entrega de obras encomendadas e não se submetia aos clientes, representando sua própria visão e imagem dos retratados, ainda que essa não fosse apreciada. ${ }^{15}$

Por outro lado, Rembrandt não fixava o valor de suas obras conforme as regras usuais da guilda de pintores (por hora trabalhada). ${ }^{16}$ Suas obras eram precificadas em mercado, um nascente mercado de arte cujo funcionamento ele próprio procurou conduzir. ${ }^{17}$

Invocando Adam Smith, Alpers chega a designar Rembrandt um "homem do mercado", com "vocação para negociar, permutar e trocar". ${ }^{18}$ A autora relata que Rembrandt frequentemente participava de leilões de arte em Amsterdam e costumava

11 ALPERS, Svetlana. O projeto de Rembrandt: o ateliê e o mercado. Tradução de Vera Pereira. São Paulo: Companhia das Letras, 2010. p. 195.

12 O seguinte trecho ilustra bem a visão de Alpers: "Rembrandt não saía de casa. O ateliê era seu mundo. Se, durante a maior parte da vida, ele não foi o gênio solitário que se dizia, mas o iniciador de um estilo peculiar de pintura, esse estilo era, por natureza, um produto do ateliê. Embora as ambições de Rembrandt fossem as mesmas que qualquer outro artista de seu tempo, elas se expressaram particularmente nesse local de trabalho: o objetivo do pintor era inventar, ou pelo menos representar, a vida exterior como se existisse no ambiente de estúdio" (ALPERS, Svetlana. O projeto de Rembrandt... cit., p. 195, 196).

13 Caracterizado, nas palavras de Alpers, pela relação em que "o mecenas comprador incentivava o profissional a identificar-se com ele e, em consequência, a servi-lo socialmente" (Id. Ibid., p. 269).

14 Id. Ibid., p. 286.

15 Id. Ibid., p. 271. Não foram raros os casos, descritos por Alpers, de devolução de retratos. Há inclusive a menção a um processo movido por um cliente para modificação de um quadro que não tinha semelhança com a modelo. O pedido era a modificação ou a devolução do adiantamento concedido pelo cliente, acrescido de juros (Id. Ibid., p. 282).

16 Id. Ibid., p. 282. Nesse trecho, Alpers inclusive demonstra como a técnica de pintura adotada por Rembrandt e o aspecto inacabado de seus quadros dificultavam a determinação do tempo despendido para executar as obras. Menciona também que por vezes Rembrandt exigia o pagamento de uma "taxa adicional" para retocar a obra, dificultando ainda mais a equivalência entre horas trabalhadas e preço (ALPERS, Svetlana. O projeto de Rembrandt... cit., p. 283).

17 ALPERS, Svetlana. O projeto de Rembrandt... cit., p. 286.

18 Id. Ibid., p. 267. 
fazer lances elevados para adquirir gravuras e pinturas. Segundo Alpers, essa era uma estratégia de Rembrandt para "elevar o crédito de sua profissão". ${ }^{19}$

Alpers faz ainda uma interessante descrição da forma de financiamento adotada por Rembrandt para produzir suas próprias obras:

A história de Rembrandt é feita de dívidas contraídas e de empréstimos renovados que circulavam como pedaços de papel representando as obras de arte ou o dinheiro em jogo.

Ele estava sempre precisando de dinheiro e disposto a prometer pinturas ou gravuras para pagar a dívida. (...) Ao que parece, alguns clientes chegaram à conclusão de que a melhor maneira de forçar Rembrandt a entregar os quadros prometidos era tê-lo como devedor. Havia, portanto, o que poderíamos descrever como um pequeno mas dinâmico mercado de notas promissórias de Rembrandt, que, dada a incerteza do pagamento e da existência real de uma obra do pintor, envolvia o mesmo espírito especulativo que os holandeses manifestavam em relação às suas tulipas ou à Bolsa de Valores de Amsterdam. ${ }^{20}$

Ao tomar empréstimos e emitir as chamadas "Rembrandt Notes" - títulos representativos de obras a serem entregues em pagamento - o pintor claramente atribuiu aos seus quadros uma "função de troca", diz Alpers, inserindo-os no "sistema de mercado" por uma lógica diversa do mecenato até então existente. ${ }^{21}$

Essas práticas, contudo, aliadas a extravagâncias praticadas pelo artista, acabaram por levar Rembrandt à insolvência. No período subsequente a ela, sua produção destinou-se a um mercado restrito, formado principalmente por seus credores. ${ }^{22}$ Mas mesmo essa declaração de insolvência é vista por Alpers como uma estratégia empresarial

19 ALPERS, Svetlana. O projeto de Rembrandt: o ateliê e o mercado. Tradução de Vera Pereira. São Paulo: Companhia das Letras, 2010. p. 288. Confira-se, por sua clareza para exprimir a tese da autora: "Enquanto outros pintores holandeses procuravam elevar o prestígio de sua profissão formando clubes ou academias em substituição às guildas de artesãos, e engajando-se no serviço de mecenas ricos ou da corte, Rembrandt preferiu fazê-lo empenhando-se em valorizar a arte no mercado. Sua escolha era claríssima. Ele não queria criar valor associando-se pessoalmente àqueles que desfrutavam de status ou poder graças ao dinheiro ou ao gosto literário, mas devido às condições do "livre' mercado" (ALPERS, Svetlana. O projeto de Rembrandt... cit., p. 288 e 289). E mais adiante: "O mercado que Rembrandt preferiu em lugar do sistema de mecenato não era simplesmente um lugar diferente onde se determinava valor; também era um modo diferente de conceber ou construir esse valor" (Id. Ibid., p. 294).

20 ALPERS, Svetlana. O projeto de Rembrandt... cit., p. 278. A mesma descrição é feita por Geert Mak na obra (MAK, Geert. Amsterdam: a brief life of the city. London: Harvill, 2001, p. 130).

${ }^{21}$ ALPERS, Svetlana. O projeto de Rembrandt: o ateliê e o mercado. Tradução de Vera Pereira. São Paulo: Companhia das Letras, 2010. p. 279 e 280.

22 ALPERS, Svetlana. O projeto de Rembrandt: o ateliê e o mercado. Tradução de Vera Pereira. São Paulo: Companhia das Letras, 2010. p. 280. 
de Rembrandt, já que limitou as cobranças e execuções movidas contra ele, permitindo a continuidade de sua atividade profissional ainda que em outras condições. ${ }^{23}$

\section{Rembrandt no Direito Privado}

Alpers revela que Rembrandt teve uma vida emblemática para a história da arte. Eu iria além: diria que também para o Direito Privado, especialmente para o Direito Comercial. Há temas de Direito Privado que me parecem encapsulados no percurso de Rembrandt.

\section{Propriedade intelectual}

Inicialmente, a Propriedade Intelectual ou o direito moral ou pessoal como prefere Oliveira Ascensão ${ }^{24}$ - de autor. O Direito Autoral funda-se na premissa de que o criador de uma obra artística deve ser protegido. Essa proteção não se limita à exclusividade na exploração econômica dessa obra, mas atinge também aspectos não patrimoniais, considerados personalíssimos, como, por exemplo, a reivindicação da paternidade da obra ou a designação como autor (crédito).

$\mathrm{O}$ estudo de Alpers inicia-se, e encerra-se, justamente com o problema da autenticidade das obras produzidas no ateliê de Rembrandt. Há indícios de que podem não ter sido pintadas por suas próprias mãos, mas foram por ele assinadas e, por isso, a ele atribuídas. ${ }^{25} \mathrm{E}$ mais que isso: respeitam um "estilo Rembrandt", têm individualidade, foram confeccionadas sob a supervisão do pintor, em seu ateliê.

A propósito de reestabelecer a verdade e reconduzir o direito autoral ao seu real titular, caberia recorrer a uma "desatribuição" da obra? O Staatliche Museen Preussischer Kulturbesitz em Berlim deveria indicar "autor desconhecido" como criador do quadro "Homem com elmo dourado" em lugar de Rembrandt? Assim o direito moral de autor cumpriria sua função?

Não me parece. Aliás, após a leitura da obra de Alpers, fiquei com a impressão de que o sistema de direito de autor, tal como atualmente estruturado, pode

23 ALPERS, Svetlana. O projeto de Rembrandt: o ateliê e o mercado. Tradução de Vera Pereira. São Paulo: Companhia das Letras, 2010. p. 280. Descrição diversa foi feita por Geert Mak. Ele narra um processo de insolvência imposto a Rembrandt e bastante tumultuado, inclusive com intervenção da igreja (MAK, Geert. Amsterdam: a brief life of the city. London: Harvill, 2001. p. 131).

24 ASCENSÃO, José de Oliveira. Direito autoral. 2. ed. Rio de Janeiro: Renovar, 1997. p. 129.

25 A frase é da própria Alpers: 'Não admira que 'Homem com elmo dourado' tenha sido considerado um Rembrandt essencial ou canônico. E assim é, ainda que sua autenticidade seja hoje duvidosa. O quadro pode não ter sido feito com suas próprias mãos, mas o velho homem pertence à tribo de Rembrandt - um artista cuja realização não pode ser reduzida à sua obra assinada." (ALPERS, Svetlana. O projeto de Rembrandt: o ateliê e o mercado. Tradução de Vera Pereira. São Paulo: Companhia das Letras, 2010). 
não estar apto a recepcionar a complexidade do caso Rembrandt e de outros artistas em situações semelhantes. Talvez Alpers não tenha sido incorreta ao intuitivamente definir o "estilo Rembrandt" como uma marca, pois é apta a distinguir os quadros por sua origem (o ateliê) e pela técnica de pintura. Observa-se aqui uma certa intersecção entre conceitos tidos por estanques na dogmática tradicional: a marca, objeto da propriedade industrial e regida por uma lógica de mercado, e o direito de autor, vinculado a valores estéticos e artísticos. ${ }^{26}$ Essa contraposição parece merecer uma profunda revisão.

\section{Empresários vs não-empresários}

Outra ordem de reflexões jurídicas diz respeito à relação de Rembrandt com o mercado. Alpers define Rembrandt coloquialmente como um empresário. ${ }^{27}$ De fato, suas práticas assemelham-se às dos comerciantes da época. Claramente há organização de fatores de produção para colocação de bens em mercado. Mas se trata de um empresário no sentido técnico do termo?

Essa indagação me conduz - por hábito docente - ao debate sobre o objeto do Direito Comercial e à tormentosa distinção entre empresários e não-empresários. $\mathrm{O}$ vigente Código Civil Brasileiro importou, não sem adaptações, ${ }^{28}$ o conceito de empresário do Código Civil Italiano de 1942. Ao fazê-lo, distingue empresário dos "profissionais intelectuais, de natureza artística, literária e científica". A premissa é a de que a profissão artística é desprovida de caráter empresarial.

Ainda que a razão esteja com Ascarelli e a explicação para essa distinção seja meramente um juízo de valor ${ }^{29}$ ou uma política legislativa, o caso Rembrandt descortina uma incongruência. Não pode o artista ser empresário? Não deve o Direito reconhecer o caráter empresarial da profissão artística?

26 A doutrina explica a dicotomia entre propriedade industrial e direito de autor da seguinte forma: ( $i$ ) a propriedade industrial tem por objeto a técnica, enquanto que o direito de autor recai sobre a estética; (ii) as criações protegidas por propriedade industrial alteram a realidade, a "natureza das coisas", enquanto que as obras de direito autoral modificam a percepção interna do destinatário; (iii) a propriedade industrial pressupõe a aplicação da criação no processo produtivo, em mercado, portanto, e o direito de autor apenas secundariamente objetiva a divulgação do conhecimento, já que sua principal finalidade é a tutela da expressão criativa do autor. Confira-se, a respeito, SILVEIRA, Newton. Propriedade intelectual. 4. ed. São Paulo: Manole, 2010. cap. 1 a 3.

27 Ainda que tenha atenuado a expressão, ao considerá-lo um "empresário em termos" por não ter - como Rubens - adotado a divisão do trabalho em seu ateliê (ALPERS, Svetlana. O projeto de Rembrandt: o ateliê e o mercado. Tradução de Vera Pereira. São Paulo: Companhia das Letras, 2010. p. 285).

28 Sobre essas adaptações, vide SZTAJN, Rachel. O que se perdeu na tradução. Revista de Direito Mercantil, Industrial, Econômico e Financeiro, São Paulo, n. 153/154, p. 7-15, jan./jul. 2010.

29 ASCARELLI, Tullio. A atividade do empresário. Revista de Direito Mercantil, Industrial, Econômico e Financeiro, São Paulo, n. 132, p. 203-215, out./dez. 2003. (Tradução de Erasmo Valladão A. N. França). ASCARELLI, Tullio. Corso di diritto commerciale: introduzione e teroria dell'impresa. 3. ed. Milano: Giuffrè, 1962. p. 161-185. 
A descrição de Alpers da organização do ateliê de Rembrandt e de sua forma de inserção no mercado desconstrói um dos mais conhecidos exemplos didáticos invocados para ilustrar a categoria dos "não-empresários". Se há tempos essa distinção carecia de sentido para mim, ficou ainda mais difícil explicá-la após a leitura da obra de Alpers.

\section{Títulos de crédito}

Além disso, é interessante observar como Rembrandt situa-se fielmente na Holanda do seu tempo, caracterizada pelo desenvolvimento do comércio, do sistema bancário e de um nascente mercado de capitais, representado pela famosa Bolsa de Amsterdam, em que se negociavam direitos sobre bulbos de tulipa. ${ }^{30}$

Nesse contexto, Rembrandt - tal como descrito por Alpers - pode ser visto como um autêntico "engenheiro comercialista". ${ }^{31}$ Ao emitir títulos representativos de suas obras - a serem confeccionadas - em contrapartida pelo adiantamento de recursos, Rembrandt alinha-se aos comerciantes, uma classe que, conforme bem descreveu Ascarelli, criou os instrumentos necessários para atender às exigências de sua atividade e do tráfico econômico. Assim surgiram a letra de câmbio, o seguro, a sociedade.

As "Rembrandt Notes" são mais um exemplo dessa inventividade. A estrutura é engenhosa: para captar recursos e financiar sua atividade, Rembrandt emitia títulos que conferiam ao credor o direito ao recebimento de uma pintura por ele confeccionada. ${ }^{32}$ Embora constituísse crédito sobre obra futura, o título tinha um valor presente - que variava conforme a perspectiva de o pintor concluir o quadro prometido e conforme sua reputação em Amsterdam - e por isso circulava. O diálogo com a teoria geral dos títulos de crédito é inevitável.

A existência e desenvolvimento de um mercado secundário dessas notas é igualmente fascinante e pode ilustrar - com cores vibrantes - explicações iniciais sobre formação e funcionamento de mercados de títulos.

30 Sobre a Bolsa de Amsterdam: ASCARELLI, Tullio. Corso di diritto commerciale: introduzione e teoria dell'impresa. 3. ed. Milano: Giuffrè, 1962. p. 38-39.

31 A expressão é - mais uma vez - de Ascarelli (ASCARELLI, Tullio. Varietà di titoli di credito e investimento. In:___Problemi giuridici. Milano: Dott. A. Giuffrè Editore, 1959. t. II. p. 702).

32 Trata-se do uso de títulos para financiamento da atividade profissional, recorrente no Brasil com as Cédulas de Produto Rural - CPR, conforme reconhecido pelo Superior Tribunal de Justiça (vide, por exemplo: REsp. 1320167/SP, j. 08.05.2014). 


\section{Insolvência}

Por fim, a insolvência de Rembrandt. Independentemente da acuidade do relato de Alpers - já que Geert Mak apresenta descrição contrastante do mesmo tema - chamou minha atenção o uso - já no século XVII - do processo de insolvência como um recurso para barrar pretensões adicionais de credores e cujo desfecho poderia ser um fresh new start para o devedor. Esses aspectos costumam ser negligenciados quando se analisam as origens do regime de insolvência na Europa continental. É interessante observar que temas hoje caros ao nosso direito das empresas em crise já estavam no caso Rembrandt. $^{33}$

\section{Desfecho}

Espero que essas reflexões sirvam para despertar o interesse pelo estudo do Direito Privado, que realmente pode ser encontrado nos mais inusitados lugares, inclusive nos livros de história da arte.

São Paulo, 11 de abril de 2015.

\section{Referências}

ALPERS, Svetlana. Rembrandt's enterprise: the studio and the market. Chicago: Chicago University Press, 1988.

ALPERS, Svetlana. O projeto de Rembrandt: o ateliê e o mercado. Tradução de Vera Pereira. São Paulo: Companhia das Letras, 2010.

ASCARELLI, Tullio. A atividade do empresário. Revista de Direito Mercantil, Industrial, Econômico e Financeiro, São Paulo, n. 132, p. 203-215, out./dez. 2003.

ASCARELLI, Tullio. Corso di diritto commerciale: introduzione e teoria dell'impresa. 3. ed. Milano: Giuffrè, 1962.

ASCARELLI, Tullio. Varietà di titoli di credito e investimento. In: Problemi giuridici. Milano: Dott. A. Giuffrè Editore, 1959. t. II.

ASCENSÃO, José de Oliveira. Direito autoral. 2. ed. Rio de Janeiro: Renovar, 1997.

33 O mesmo concluiu Beirne em estudo comparativo entre a cessio bonorum pleiteada por Rembrandt e o vigente direito falimentar americano. Vide, a respeito, Beirne, Brian Logan. Painted into a corner: Rembrandt's bankruptcy today. Journal of Transnational Law and Policy. v. 18. p. 90-107, 2008-2009. 
BEIRNE, Brian Logan. Painted into a corner: Rembrandt's bankruptcy today. Journal of Transnational Law and Policy, v. 18. p. 90-107, 2008-2009.

KRAMER Hilton. Rembrandt as Warhol: Svetlana's Alpers Enterprise. The New Criterion. Abril de 1988. Disponível em: <http://www.newcriterion.com/articles.cfm/Rembrandt-as-Warhol-Svetlana-Alpers-s--Enterprise--5992>. Acesso em: 11 abr. 2015.

MAK, Geert. Amsterdam: a brief life of the city. London: Harvill, 2001.

SILVEIRA, Newton. Propriedade intelectual. 4. ed. São Paulo: Manole, 2010.

SZTAJN, Rachel. O que se perdeu na tradução. Revista de Direito Mercantil, Industrial, Econômico e Financeiro, São Paulo, n. 153/154, p. 7-15, jan./jul. 2010. 
